\author{
Available online at https://www.rjtl.org \\ Volume: 1, Issue: 2, 47-52, 2020 \\ ISSN: 2708-3632 \\ DOI: https://doi.org/10.46590/rjtl.2020.010203
}

\title{
An Innovative Design Experimentation of Applying Tie and Dye Technique on Traditional Kerala Handloom Saree.
}

\section{Suparna M G \\ Assistant Professor, Department of Home Science, Vimala College (Autonomous), Thrissur}

Paper History

Received : July 2020

Accepted : August 2020

Published : August 2020

Corresponding Author

Suparna M G

smgwarrier06@gmail.com

\begin{abstract}
Handloom industry is a traditional industry in India which nurtures and preserves the ancient weaving skills which are unique to each region. However, with the invention of the power loom, the handloom industry is declining all over India. Kerala has a rich handloom history and the traditional costumes of Kerala have a special reputation all over India for its fineness of count and texture. Traditional wears of Kerala are specially made in different districts of Kerala and one among them is by the Devanga Chettiar community at Kuthampully in Thrissur district. Tie and dye is one of the most acceptable and vibrant resist technique which is seen in the states of Gujarat and Rajasthan. The present study was focused on the significance of value addition on traditional Kerala sarees of Kuthampully by incorporating various shibori patterns as a replacement to the golden borders. The articles prepared were subjected to evaluation for its product aesthetics, feasibility and suitability of price. The two viewpoints considered for evaluation were the manufacturer's point of view and the customer point of view.
\end{abstract}

Keywords: Handloom industry, Tie and Dye, Traditional Kerala saree

Citation: Suparna M G, An Innovative Design Experimentation of Applying Tie and Dye Technique on Traditional Kerala Handloom Saree, Research Journal of Textile and Leather, 1(2), 47-52, 2020.

\section{INTRODUCTION}

Handloom industry plays a vibrant role in the rich cultural heritage of India. It stands unique in terms of its quality products, artistic touch and its unique texture. It also occupies a distinct place in the Indian economy. It also gives gainful employment opportunities to men and women. This can be regarded as the supporting pillars of the weaving community. The eco-friendly energy-saving products thus produced enhances sustainable development. [1].

India's handloom sector is spread across different states. Even being a small state, the handloom industry is very prominent in Kerala. The handloom history of Kerala dates back to the 15 th century when the British, French and Portuguese people visited Kerala. The things like spices, ivory and the beauty of handloom fabrics attracted them. They began to purchase large quantities of these products and exported it to their countries [2]. The handloom fabrics were initially woven specially for the royal class during that time. The major handloom weaving clusters where traditional wears of Kerala are made at Balaramapuram of Travancore region and Kuthampully of Thrissur district. The traditional wears of Kerala consist mainly of Mundum neriyathu, Set Mundu and the Kerala saree.
At Kuthampully, it is specially made by the Devanga Chettiar community who originally belong to the Mysore region of Karnataka and had shifted their looms to Kuthampully for weaving royal attires for the Raja of Kochi Palace. Most of the Kuthampully weavers have their roots in Mysore, Karnataka. The 500 -year old story that explains this transition to Kerala from Mysore says that the rulers of Kollengode and Cochin invited Mysore's famous weavers of Devanga community to become the official weavers of the royal family. In September 2011, the Kuthampully sarees received exclusive intellectual property rights through the Geographical Indication Act. But even before this, weaving was an integral part of this village and it is impossible to find a single house without its traditional loom despite the big handloom production units that have sprouted across Kerala [3].

Kerala saree is generally a single piece of cloth which is considered as the cultural costume of Malayali community. It was attributed as the royal attire with the beauty and charm of golden borders on the plain offwhite fabric [4]. Traditionally mundum neriyathum was worn by the royal class as an everyday attire and also for festive occasions. Later it was replaced by the Kerala saree due to its convenience. It is a handloom 
designed material which enhances its glamour through the intrinsic borders soaked in the colour of pure gold. This saree is considered to be the most auspicious attire for women in Kerala [5].

Considering Indian traditional craft, tie and dye are also one of the most widely accepted resist technique in India which is also known as Bandhini or Bandhej. It is difficult to trace the origin of this craft to any particular area but according to the available literature, it was first developed in Jaipur. It is continued by the people who live in the desert region of Gujarat and Rajasthan to bring out colours contrary to their dull life in these dry areas. The process of tie and dye typically consist of folding, twisting, pleating or crumpling fabrics or garments and then binding it with strings or rubber bands followed by application of dyes.

The demand for set sarees is noted low as they are used only during special occasions in Kerala. Due to its off white colour, Kerala saree is not popular among places other than South India. As a concept of value addition, innovation and popularization, it is envisaged that by incorporating colourful tie and dye designs, the monotony of using golden kasavu border and off-white body alone in Kerala saree is expected to be replaced. The application of tie and dye technique on the borders and Pallav would bring out a contrast to the pale offwhite body of Kerala saree. Hence the proposed study is intended to develop a colourful design alternative to traditional Kerala handloom saree by incorporating tie and dye techniques.

\section{MATERIAL AND METHODS}

\subsection{Collection of Raw Materials}

The main raw materials for the study included Traditional Kerala off- white fabrics, dyes and auxiliary chemicals and tie-dye accessories.

\subsubsection{Collection of Handloom Sarees}

The decision of using handloom fabric instead of power loom fabric was to promote the handloom sector of Kerala. The handloom off-white fabric of the traditional Kerala saree was sourced as the base fabric. It was specially woven without the golden borders by the weavers of Kuthampully in Thrissur district.

\subsection{Sample Design Development}

Since tie and dye is a handcraft, sample design development was necessary to finalise the rate of dye absorption, and the visibility of design effect on the fabric.

\subsubsection{Selection of Suitable Tie and Dye Designs}

To eliminate the monotony of the traditional motifs such as peacock, mango and floral, geometrical patterns were involved to give a different look to the saree. The designs were mainly concentrated on the Japanese shibori tie and dye and were to be done only on the borders and Pallavas. Vibrant colour borders and Pallavas were used as the attractive element in the attire. The varied designs of tie and dye in the platform of Kerala saree were different in their look from one another.

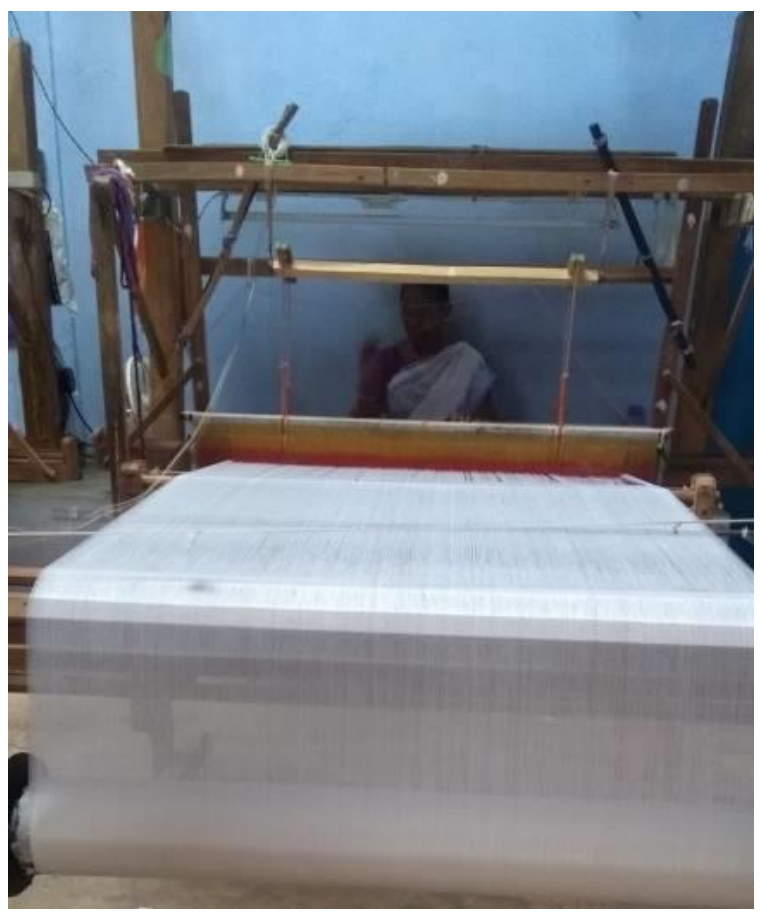

Figure 1. Handloom

\subsubsection{Sample Development of Selected Designs}

The selected handloom fabric was cut into small pieces and then it was tied according to the design required. These samples were done to test different tie and dye effects and the rate of dye absorption on the fabric. Five out of the samples were chosen for further study.

Design 1: The borders were stitched with straight running stitches throughout the saree and the pallav was stitched with an arc-shaped design.

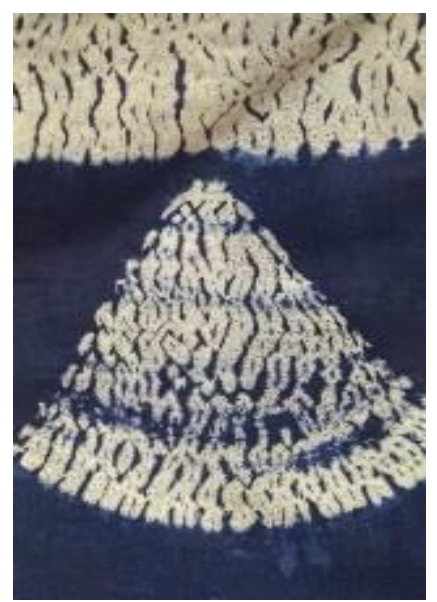

Figure 2. The borders were stitched with straight running stitches throughout the saree 
Design 2: The zigzag pattern was used for the pallav and the borders were dipped in the same colour as the pallav.

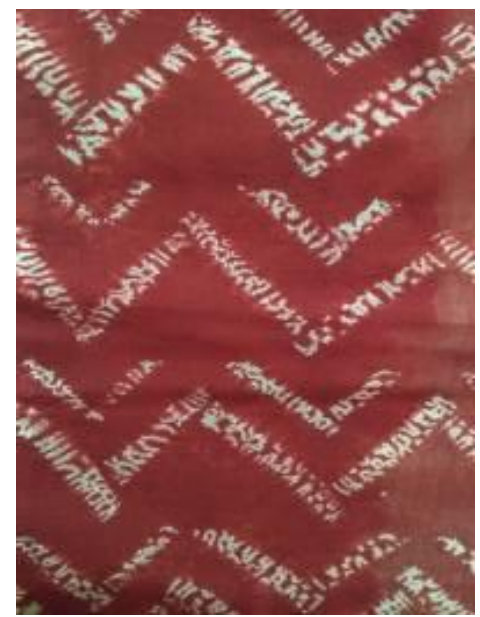

Figure 3. The zigzag pattern used for the pallav and the borders dipped in the same colour as the pallav.

Design 3: Diamond shapes were used for the third saree. Smaller size diamonds were used for borders and larger diamonds were used for the pallav.

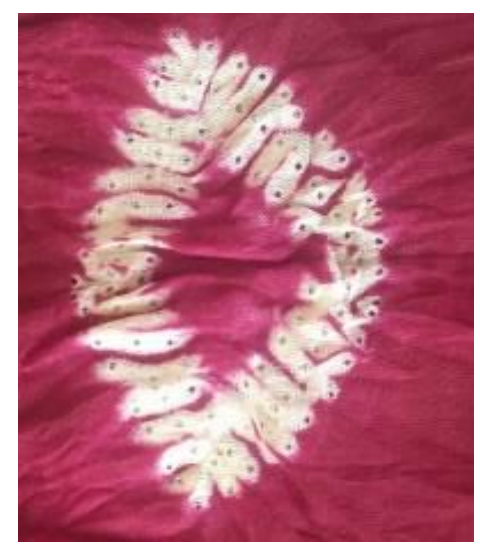

Figure 4. Diamond shapes

Design 4: Borders and pallav were decorated with triangular patterns with continuous running stitches inside the triangle.

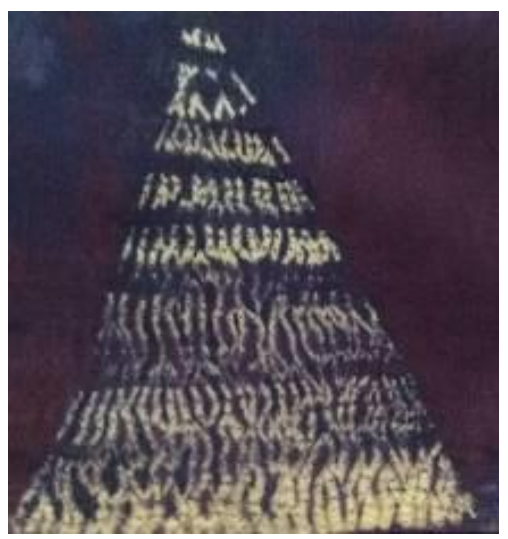

Figure 5. Borders and pallav
Design 5: The fifth saree was based on the Leheriya method. Borders and pallav were rolled using plastic pipe. It was then tied using thread at regular intervals to give the pattern.

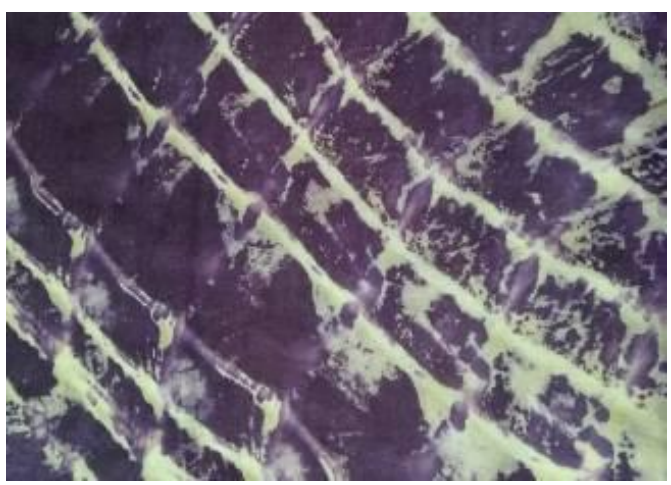

Figure 6. Design Leheriya method.

\subsection{Adaptation of Developed Designs on the Handloom Saree}

The adaptation process included the following steps

\subsubsection{Preparation of Saree}

The handwoven Kerala saree was immersed in a bath containing Luke warm water and soap oil. This is considered as the preparatory process to remove the starch and other impurities present on the fabric. The fabric was soaked in water and kept overnight. It was then rinsed and squeezed to remove the excess water and then dried under sunlight.

\subsubsection{Tying of Designs}

The selected shibhori designs were transferred to the borders and pallavs of Kerala saree using carbon paper and tracing paper. Running stitches were given over the designs on four sarees. It was then pulled and tied securely to resist the penetration of dyes. For the fifth saree, the fabric was rolled using a plastic pipe and the thread was tied over the fabric to create the selected pattern.

\subsubsection{Dyeing of Saree}

The handloom saree was dyed using Naphthol dyes. The 5 different shades used were Blue, Red, Magenta, Purple and Double shade. The colour shades were chosen to bring out a bright contrast to the off white body of the saree. The borders and pallavs were dyed separately protecting the other portions from dye penetration. The entire process was divided into two stages.

\subsubsection{Naphthol preparation}

$10 \mathrm{gms}$ of Naphthol was taken and 4-5 tablespoon was used to make a paste. Half cup of water was boiled and $10 \mathrm{gms}$ of caustic soda was added to the boiling Naphthol until it clears. 

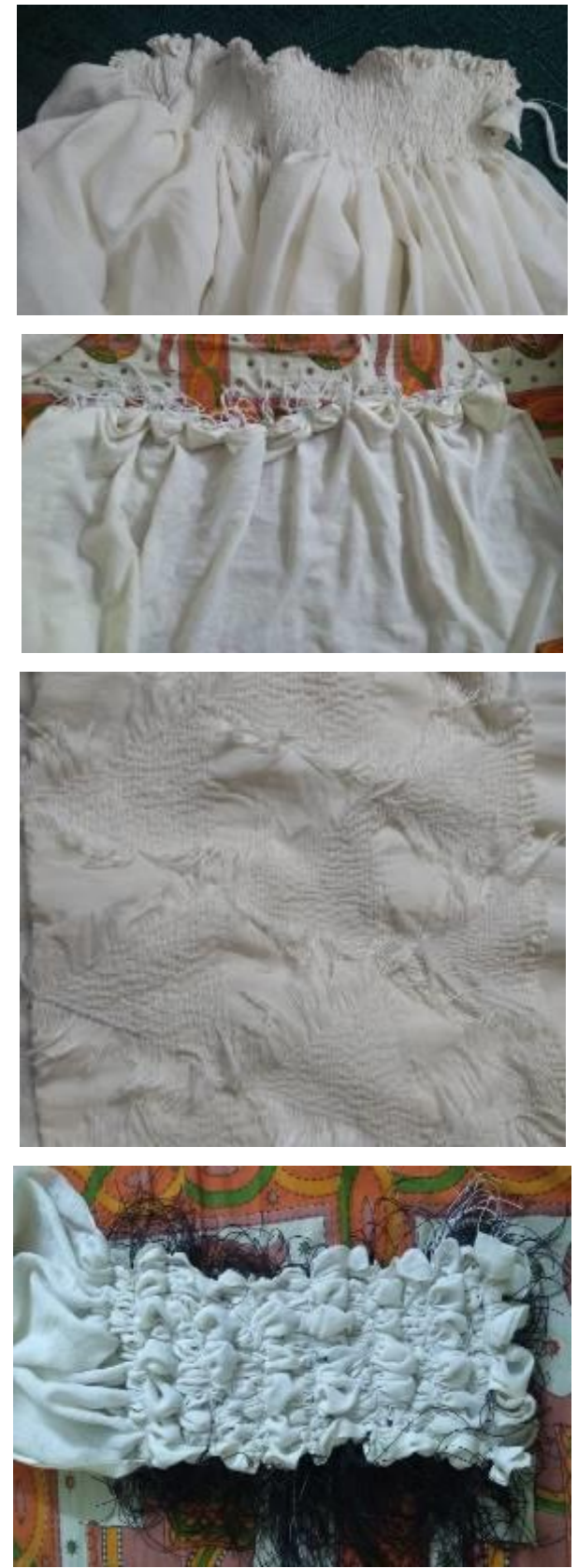

Figure 7. Fabric Tying

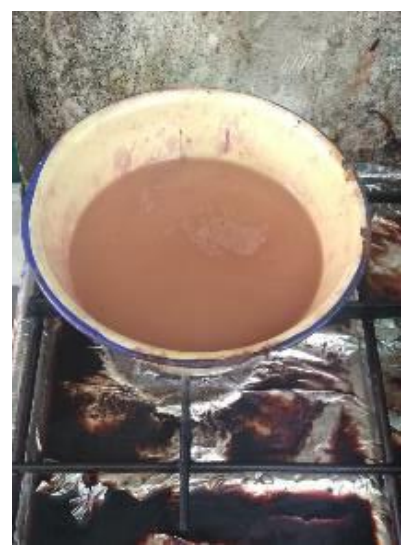

Figure 8a. Naphthol Preparation

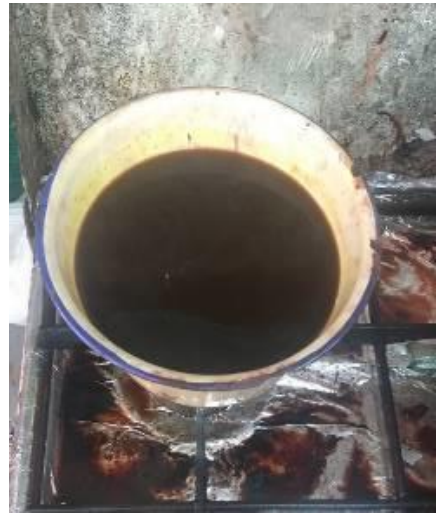

Figure 8b. Naphthol Preparation

\subsubsection{Base preparation}

$10 \mathrm{gms}$ of the base was taken and $16 \mathrm{ml}$ of hydrochloric acid was added. Half cup of water was added. $3 \mathrm{gms}$ of sodium nitrite solution was added to the solution. $20 \mathrm{gms}$ of sodium acetate solution and $30 \mathrm{gms}$ of aluminium sulphate was added.

The fabric was first dipped in the Naphthol solution for 15-20 minutes and then dipped in the base solution for another 20 minutes. It was then taken out and squeezed. The fabric was washed thoroughly to remove the excess dye. The depth of shade was kept to $5 \%$ to get a darker shade.
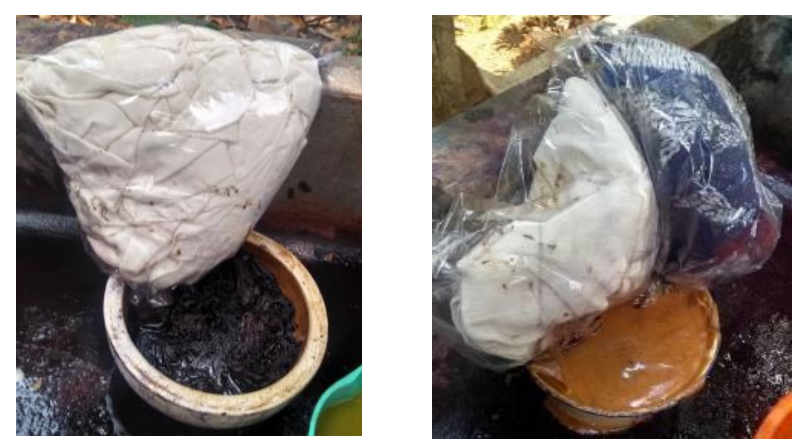

Figure 9. Base Preparation

\section{RESULTS AND DISCUSSION}

\subsection{Evaluation of design and Feasibility}

The products prepared were subjected to evaluation for its product aesthetics, feasibility and suitability of price. The two viewpoints considered here were the manufacturer's viewpoint and the customer's viewpoint.

\subsubsection{Manufacturer's Point of View}

An exhibition of these final sarees was arranged for the members of Kuthampully Handloom Society and their opinions were taken as the manufacturer's viewpoint. 
A ranking Performa was used for this purpose. The attributes were colour combination, uniqueness in designs, utility, overall appearance and suitability of cost range of products.

Table1.Feasibility Index of Products

\begin{tabular}{ccc}
\hline Article & $\begin{array}{c}\text { Total Marks } \\
(300)\end{array}$ & Feasibility \\
\hline Article I & 272 & $91 \%$ \\
Article II & 270 & $90 \%$ \\
Article III & 274 & $91 \%$ \\
Article IV & 259 & $86 \%$ \\
Article V & 266 & $89 \%$ \\
\hline
\end{tabular}

According to the manufacturer's point of view, Article III was ranked best out of five with a feasibility index of $91 \%$.

Table 2. Evaluation of Suitability of Price

\begin{tabular}{cccc}
\hline Articles & Low & Adequate & High \\
\hline Article I & $44 \%$ & $52 \%$ & $4 \%$ \\
Article II & $64 \%$ & $32 \%$ & $4 \%$ \\
Article III & $60 \%$ & $36 \%$ & $4 \%$ \\
Article IV & $64 \%$ & $32 \%$ & $4 \%$ \\
Article V & $56 \%$ & $40 \%$ & $4 \%$ \\
\hline
\end{tabular}

$44 \%$ of weavers said that the price was low for Article I, $52 \%$ of weavers said that the price was adequate while $4 \%$ of weavers said that the price was high.64\% of weavers said that the price was low for Article II, $32 \%$ of weavers said that the price was adequate while $4 \%$ of weavers said that the price was high. $60 \%$ of weavers said that the price was low for Article III, $36 \%$ of weavers said that the price was adequate while $4 \%$ of weavers said that the price was high. $64 \%$ of weavers said that the price was low for Article IV, $32 \%$ of weavers said that the price was adequate while $4 \%$ of weavers said that the price was high. $56 \%$ of weavers said that the price was low for Article V, $40 \%$ of weavers said that the price was adequate while $4 \%$ of weavers said that the price was high.

\subsubsection{Customer's Point of View}

A target group consisting of 25 women between the age group of 35-50 years were selected as customers for evaluation. Their opinion was taken as the customer point of view. A ranking Performa was used for this purpose. The attributes were colour combination, uniqueness in designs, utility, overall appearance and suitability of cost range of products.

The feasibility index for Article $1 \mathrm{~V}$ was $96 \%$ according to the customer point of view and was ranked the best out of five (Ref: Table 3).

$64 \%$ of consumers said that the price was low for Article I while $36 \%$ of consumers said that the price was adequate. $60 \%$ of woman consumers said that the price was low for Article II while $40 \%$ of consumers said that the price was adequate. $52 \%$ of consumers said that the price was low for Article III while $48 \%$ of consumers said that the price was adequate. $64 \%$ of consumers said that the price was low for Article 1V while $36 \%$ of consumers said that the price was adequate. $72 \%$ of consumers said that the price was low for Article V while $28 \%$ of consumers said that the price was adequate

From the studies done, it is clear that $90 \%$ of consumers were very positive on the experimentation done on the Kerala saree. $95 \%$ of consumers commented that the developed products were very innovative and $95 \%$ of consumers were likely to buy the products. $90 \%$ of consumers preferred handloom sarees due to its quality and comfort (Ref: Table 4).

From the studies, $90 \%$ of weavers were ready to accept the new design experimentation but $45 \%$ of weavers were not aware of shibhori techniques and its applications.

Table 3.Feasibility Index of Products

\begin{tabular}{lcc}
\hline Article & $\begin{array}{c}\text { Total } \\
\text { Marks(300) }\end{array}$ & Feasibility \\
\hline Article I & 279 & $93 \%$ \\
Article II & 286 & $95 \%$ \\
Article III & 283 & $94 \%$ \\
Article IV & 288 & $96 \%$ \\
Article V & 280 & $93 \%$ \\
\hline
\end{tabular}

Table 4.Evaluation of Suitability of Price

\begin{tabular}{cccc}
\hline Articles & Low & Adequate & High \\
\hline Article I & $64 \%$ & $36 \%$ & - \\
Article II & $60 \%$ & $40 \%$ & - \\
Article III & $52 \%$ & $48 \%$ & - \\
Article IV & $64 \%$ & $36 \%$ & - \\
Article V & $72 \%$ & $28 \%$ & - \\
\hline
\end{tabular}

\subsubsection{Output of Designs}
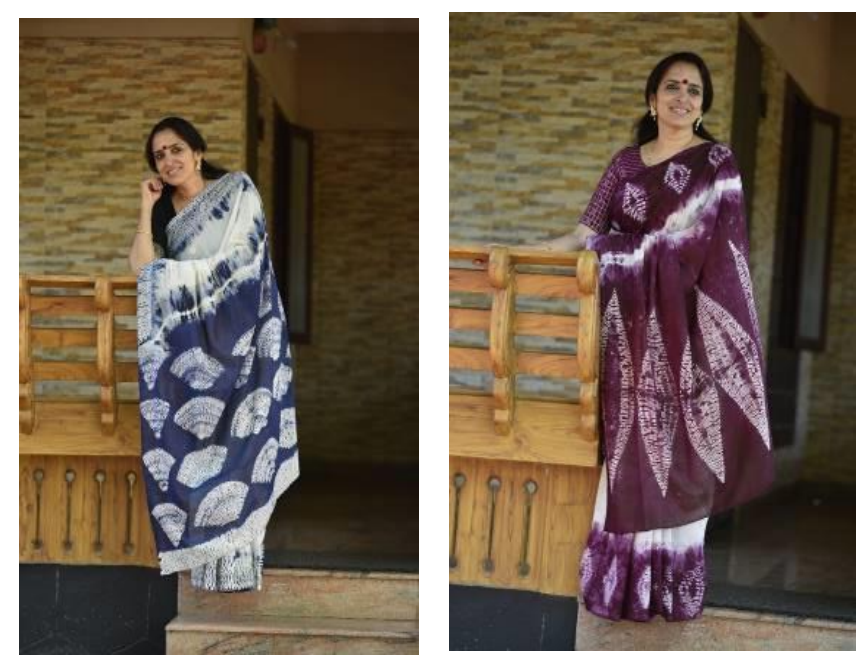

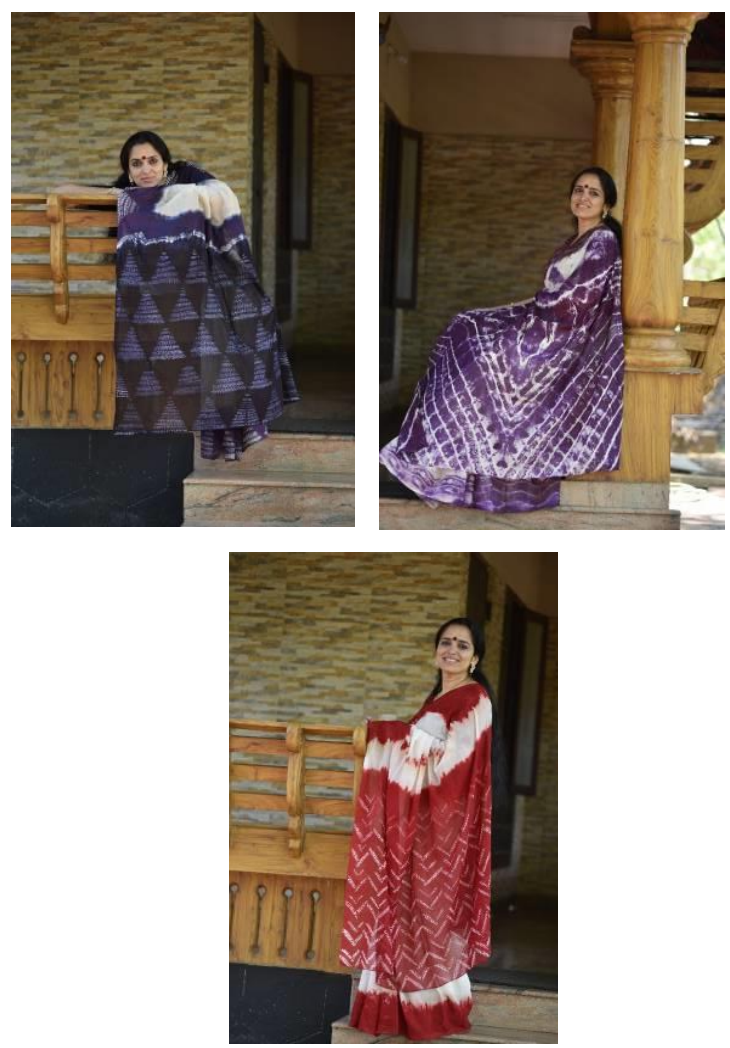

Figure 10. Design Outputs

\section{CONCLUSIONS}

The tradition of weaving cloth by hand constitutes one of the richest and most resilient aspects of cultural heritage. The level of artistry and intricacy achieved by handloom fabrics is unique and beyond the scope of modern machines. The hand-woven fabrics are unique in their flexibility and versatility, permitting experimentation and encouraging innovation. Handloom products have a distinct place in the world of fabrics. The strength of this sector lies in introducing innovative and new designs. The handloom industry in Kerala is one of the major industry which needs care and attention. Kerala sarees are symbolic of Kerala's culture and it is considered as the cultural costume of women of the Malayali community.

Each state has its traditional fabrics and handicrafts. Tie and dye are one among the traditional handicraft unique to Gujarat and Rajasthan. The use of tie and dye technique on the borders and pallavs of the handloom saree helps to bring an innovative value addition in Kerala sarees. The monotony of using golden kasavu borders in the pale off-white saree is effectively replaced by the colourful tie and dye technique. The articles developed is design experimentation on traditional attire. The use of handloom fabrics in this project is intended to promote the handloom sector of the state. The art of shibhori is new to the weavers of Kuthampully village. Patterns were mostly concentrated to bold geometric designs replacing the traditional motifs used in Kerala sarees. The fusion of vibrant tie and dye with the pale off white saree brings a new range of product extension to the zone of Kerala saree.

\section{ACKNOWLEDGEMENTS}

I express my profound sense of gratitude to my guide Mrs.Liz Thankom Mathew, Head, Department of Fashion Technology for her continued guidance, valuable suggestions, unreserved help and meticulous guidance during the study. It is a matter of real privilege for me to express my profound sense of gratitude to $\mathrm{Mr}$ Prasanna Kumar, Retd. Fine Arts Professor for his untiring help and supervision during the investigation.

\section{REFERENCES}

[1]. Shamitha.K. V, Dr.P. Balasubramanian, SocioEconomic Condition of Handloom Weavers: A Study with Special Reference to Handloom Weavers Co-Operative Society in Kannur District.

[2]. Study \& Documentation of Balaramapuram Sarees \& Fine Cotton fabrics: The Pride of God's Own Country, Textiles Committee Ministry of Textiles Government of India Mumbai.

[3]. Power looms may anger the goddess': The story of a unique weaver's village in Kerala", Retrieved from www.scroll.in

[4]. Saree Weaving - Thrissur, Kerala, Retrieved from www.dsource.in

[5]. Kerala Kasavu Saree", Retrieved from www.utsavpedia.com 